\title{
Cianobacterias y cianotoxinas en ecosistemas límnicos de Uruguay
}

\section{Cyanobacteria and cyanotoxins in freshwaters of Uruguay}

\author{
Bonilla, Sylvia ${ }^{(1)(2)}$, Haakonsson, Signe ${ }^{(1)(2)}$, Somma, Andrea ${ }^{(1)(2)}$, Gravier, Ana ${ }^{(3)}$, Britos, Anamar (3), Vidal, Leticia ${ }^{(1)(3)}$, \\ De León, Lizet $^{(1)(4)}$, Brena, Beatriz, M. (1)(6)(7), Pírez, Macarena ${ }^{(8)}$, Piccini, Claudia (1)(5), Martínez de la Escalera, Gabriela ${ }^{(5)}$, \\ Chalar, Guillermo (2), González-Piana, Mauricio (2), Martigani, Fátima (1)(2), Aubriot, Luis (1)(2) \\ (1) Grupo de Fisiología y Ecología de Fitoplancton - (2) Sección Limnología, Facultad de Ciencias, Universidad de la República - \\ (3) Área Hidrobiología de la Gerencia de Gestión de Laboratorios, Obras Sanitarias del Estado, OSE - (4) Dirección Nacional de \\ Medio Ambiente, División Calidad Ambiental, Departamento de Evaluación Ambiental Integrada, MVOTMA - \\ (5) Departamento de Microbiología, Instituto de Investigaciones Biológicas Clemente Estable, IIBCE - (6) Servicio de Evaluación \\ de la Calidad y Control Ambiental, Intendencia de Montevideo, IM - (7) Cátedra de Bioquímica, Facultad de Química, \\ Universidad de la República - ${ }^{(8)}$ Cátedra de Inmunología, Facultad de Química, Universidad de la República.
}

Contacto: sylvia.e.bonilla@gmail.com

RECIBIDO: 30/1/2015 - APROBADO: 1/10/2015

\begin{abstract}
Resumen
Las floraciones de cianobacterias en cuerpos de agua dulce constituyen un problema mundial, asociado a la eutrofización (enriquecimiento de nutrientes) y cambios hidrológicos de los ecosistemas. En este estudio se generó una base de datos históricos ( $\mathrm{n}=3061$ para 64 ecosistemas, de 1980 a 2014), elaborada por un grupo de trabajo interinstitucional (OSE, DINAMA, IM, Universidad de la República e IIBCE), y se analizó la distribución de cianobacterias planctónicas y de cianotoxinas (microcistina, saxitoxina y cilindrospermopsina) en Uruguay. Los valores de clorofila a y nutrientes totales indicaron procesos de eutrofización en diversos ecosistemas. En dos mapas georreferenciados se visualiza la distribución de cianobacterias en el país, según indicadores cuantitativos globales, y de la microcistina (cianotoxina más frecuente). En estos mapas se destacan los embalses (Río Uruguay y Río Negro) y las playas del Río de la Plata como las zonas de mayor riesgo de exposición a cianobacterias según las categorías de la Organización Mundial de la Salud para aguas recreacionales. Además, se analizaron muestras de floraciones (espuma) y se cuantificó $20 \mathrm{mg} \mathrm{L}^{-1}$ de microcistinas totales y la presencia de genes que sugieren diferentes variedades de microcistinas. Se generó información básica que podrá ser útil para programas de monitoreo nacionales e investigación.

Palabras clave: Calidad de agua, fitoplancton, eutrofización, floraciones, toxicidad, monitoreo ambiental.
\end{abstract}

\begin{abstract}
Cyanobacterial blooms are a worldwide environmental problem. This phenomenon is typically associated with eutrophication (nutrient enrichment) and changes in hydrology. In this study we analysed the distribution of planktonic cyanobacteria in Uruguay and their toxins (microcystin, saxitoxin and cylindrospermopsin), working with a interagency team (OSE, DINAMA, IM, University of the Republic and IIBCE). A historical data base ( $\mathrm{n}=3061$ for 64 ecosystems, years 1980-2014) was generated. Differences between lotic and lentic ecosystems were found in terms of chlorophyll a and nutrient concentrations, usually indicating eutrophication. Two geo-referenced maps for the country were generated with cyanobacteria biomass indicators and the most relevant toxin (microcystin), according to risk levels suggested by the World Health Organization for recreational waters. The areas of greatest risk of exposure were the reservoirs of large rivers (Uruguay and Río Negro) and Río de la Plata beaches. In the second part of the study, up to $20 \mathrm{mg} \mathrm{L}^{-1}$ of microcystin was quantified in bloom (scum) samples, as well as the presence of genes that suggest more microcystin varieties, potentially with greater toxicity. This study provides basic information about the distribution of cyanobacteria in Uruguayan freshwaters that will be useful for national monitoring programs and scientific research.
\end{abstract}

Keywords: Water quality, phytoplankton, eutrophication, blooms, toxicity, monitoring.

\section{Introducción}

Las floraciones de cianobacterias planctónicas constituyen una problemática que afecta la calidad de agua de los ecosistemas límnicos en el mundo entero (Paerl y Otten, 2013).
Estos organismos procariotas pueden crecer rápidamente acumulando altas biomasas y dominando el fitoplancton, fenómeno conocido como floración, lo que interfiere con el uso del agua como recurso. En particular se destacan las cianotoxinas, metabolitos que pueden provocar la muerte en 
mamíferos y/o ser cancerígenos y teratogénicos debido a la exposición a bajas dosis por períodos prolongados (Chorus y Bartram, 1999). Las toxinas más comunes son las microcistinas (potentes hepatotoxinas) que pueden presentarse en más de 90 variantes químicas de diferente toxicidad (Niedermeyer, 2013). La exposición de la población humana a cianotoxinas puede darse de diversas formas, siendo las más comunes la vía oral y el contacto directo.

Las floraciones de cianobacterias se generan por factores asociados a características regionales, como la ubicación geográfica del cuerpo del agua y los impactos del cambio climático, factores locales, como el tipo y uso del suelo en la cuenca, y alteraciones hidrológicas de los cursos de agua (Paerl y Otten, 2012). El incremento en la carga de nutrientes, como consecuencia de la agricultura y de diversas actividades industriales en la cuenca, constituye la principal causa de eutrofización de los ecosistemas límnicos (Moss, 1998). El aumento en el aporte del nitrógeno y fósforo promueven el desarrollo de las floraciones de cianobacterias. Los impactos antrópicos en la hidrología de los ambientes lóticos, como por ejemplo la construcción de embalses, también puede favorecer el crecimiento de cianobacterias al aumentar el tiempo de residencia del agua (Moss, 1998).

Los programas de monitoreo ambiental para dar alertas tempranas sobre el aumento de cianobacterias utilizan indicadores biológicos indirectos (clorofila fitoplanctónica) o directos (células o biovolumen de cianobacterias), e indicadores ambientales como cambios en la temperatura o el pH, entre otros (Chorus y Bartram, 1999; Chorus, 2012). La Organización Mundial de la Salud (OMS) ha elaborado guías y recomendaciones basadas en niveles de riesgo de efectos adversos para la salud (riesgo bajo o improbable, moderado y alto) para agua potable y agua recreacional, según se traspasen diferentes umbrales de los indicadores biológicos (Chorus y Bartram, 1999).

La clorofila $a$ ha sido el indicador históricamente más utilizado en programas de monitoreo como indicador de la biomasa de fitoplancton, ya que es robusto, relativamente sencillo de estimar y porque existen numerosos modelos predictivos disponibles basados en esta variable (Moss, 1998; Chorus y Bartram, 1999). Sin embargo, al ser un indicador global de la biomasa fitoplanctónica, tiene baja precisión a la hora de predecir cianobacterias. Por el contrario, el biovolumen de las cianobacterias es el indicador más preciso de la biomasa, si bien requiere personal altamente capacitado e insume mucho tiempo de análisis (Sournia, 1978). Más recientemente se han comenzado a incorporar otros indicadores de medición simple y rápida que puedan brindar información en tiempo real, como los pigmentos in vivo, o de potencial peligrosidad, como los genes de cianotoxinas (Chorus, 2012).

No obstante, la OMS recomienda que la selección de las variables indicadoras y los niveles de acción respondan a la situación de cada país en cuanto a su ubicación geográfica, red hidrográfica, uso del suelo y niveles naturales de productividad fitoplanctónica (Chorus, 2012). Esto requiere el conocimiento exhaustivo de la situación local sobre la magnitud de la distribución de las cianobacterias y de las cianotoxinas y el tipo de ecosistema que afectan con mayor frecuencia.

Los sistemas de información geográfica (SIG) son una herramienta versátil que permite resumir y visualizar espacialmente gran cantidad de información. Además, permiten integrar la complejidad de distintos componentes (cuencas hidrográficas, suelo, actividades humanas) que afectan la calidad del agua y condicionan su gestión. Por lo tanto, un estudio exhaustivo y global sobre la distribución de las floraciones de cianobacterias a nivel país es un punto de partida necesario que puede contribuir a establecer zonas de riesgo y a determinar valores guía válidos para las condiciones locales.

\section{Situación actual en Uruguay}

Las floraciones de cianobacterias son frecuentes en cuerpos de agua superficiales del país, como lagos artificiales (Bonilla, et al., 1995; Vidal y Kruk, 2008; Fabre, et al., 2010; Aubriot y Bonilla, 2012), lagunas costeras (Pérez, et al., 1999; Bonilla y Conde, 2000; Bonilla, et al., 2006; Vidal y Kruk, 2008; Conde, et al., 2009; Vidal, et al., 2009; Pacheco, et al., 2010), ríos y embalses (Quirós y Luchini, 1982, Ferrari, et al., 2011; O'Farrell, et al., 2012; Chalar, et al., 2014) y costas del Río de la Plata (revisado en: Ferrari y Vidal, 2006; Sienra y Ferrari, 2006). En la compilación realizada por Bonilla (2009) se registraron 26 especies de cianobacterias formadoras de floraciones en diversos tipos de ecosistemas límnicos del país. Se han detectado microcistinas en floraciones de cianobacterias del complejo Microcystis aeruginosa en playas del Río de la Plata (De León y Yunes, 2001; Sienra y Ferrari, 2006; Pírez, et al., 2013), en embalses del Río Negro (González-Piana, et al., 2011), muestras del Río Uruguay (Bella Unión) con diversas especies de cianobacterias (Gravier, et al., 2009) y diversos cuerpos de agua (microcistina-LR) (Simoens, 2009). También se han reportado saxitoxinas (neurotoxinas) en cepas de Cylindrospermopsis raciborskii aisladas de diversos lagos (Piccini, et al., 2011). La información disponible sobre floraciones de cianobacterias en diversos cuerpos de agua de Uruguay se encuentra dispersa y aún no existe un estudio integrado de la situación general a nivel país. Además, aún no se ha clasificado la información según las categorías de la OMS a los efectos de evaluar el riesgo potencial de esta problemática a nivel país. Tampoco se cuenta con una evaluación exhaustiva de los tipos de cianotoxinas (señaladas anteriormente) de las floraciones del país. Un análisis con herramientas SIG podría ser un insumo inicial clave para evaluar la distribución de las floraciones de cianobacterias en forma sinóptica e identificar necesidades de gestión.

En Uruguay actualmente varias entidades llevan adelante programas de monitoreo sobre la calidad de agua y la presencia de cianobacterias en cuerpos de agua destinados a diversos fines (potabilización, recreación, industria). Se destacan los programas de OSE (agua a potabilizar), DINAMA (aguas recreacionales), Comisión Administradora del Río Uruguay (CARU), LATU-UPM y DINAMA (calidad de agua del Río Uruguay) y diversos monitoreos con fines científicos que lleva adelante la Universidad de la República. Sin embargo, en Uruguay no existe reglamentación ambiental nacional para el monitoreo de las cianobacterias en aguas recreacionales (Vidal y Britos, 2012), aunque está en revisión el Decreto ministerial 253/79 (Uruguay, 1979) y sus modificativos. En aguas para consumo humano, OSE considera un valor máximo permitido (VMP) de $1 \mu \mathrm{gL}^{-1}$ de microcistina - LR de acuerdo a la norma UNIT 833:2008 (Instituto Uruguayo de Normas Técnicas, 2008), normativa nacional a partir del Decreto del Poder Ejecutivo 375/11 (Uruguay, 2011) (Britos, et al., 2009; Vidal y Britos, 2012) y de acuerdo a las recomendaciones de la OMS.

El primer objetivo de este trabajo fue realizar un análisis sinóptico de la presencia de las cianobacterias planctónicas y de cianotoxinas en los cuerpos de agua superficiales del país, 
en función de indicadores globales que utilizan estimadores de biomasa de cianobacterias y concentración de cianotoxinas, para ser categorizados según los niveles guía propuestos por la OMS para aguas recreacionales. El segundo objetivo fue analizar la presencia de microcistinas en muestras puntuales y la presencia de genes de esta toxina, para explorar nuevos métodos rápidos de detección de cianobacterias tóxicas. Para ello se trabajó con un abordaje interdisciplinario e interinstitucional (OSE, Intendencia de Montevideo, DINAMA, Instituto de Investigaciones Biológicas Clemente Estable y Universidad de la República).

\section{Materiales y Métodos}

Se generó una matriz con indicadores cuantitativos de cianobacterias (células de cianobacterias totales y biovolumen de cianobacterias totales, abreviado como: cél-C y BV-C, respectivamente) y fitoplancton total (concentración de clorofila $a$, clo $a$ ), presencia de "espuma" (concentración de clo $a>200 \mu \mathrm{g} \mathrm{L}^{-1}$ ), cianotoxinas (microcistinas, saxitoxinas y cilindrospermopsina), temperatura del agua, nitrógeno total y fósforo total. Las fuentes bibliográficas utilizadas fueron artículos científicos, tesis, informes técnicos de DINAMA UPM, IM, CTM, UTE, Sección Limnología de la Facultad de Ciencias (Chalar, et al., 1993; Conde, et al., 1995; Gorga, et al., 1996a; Gorga, et al., 1996b; Gorga, et al., 1996c; Gorga, et al., 1997; Conde, et al., 1998; Gorga, et al., 1998; Scasso, et al., 2001; Bonilla, 2002; Kruk, et al., 2002; Bonilla, et al., 2005; Chalar, 2006; Feola, et al., 2006a; Feola, et al., 2006b; Kruk, et al., 2006; Boccardi, et al., 2007; Feola, et al., 2007a; Feola, et al., 2007b; Aubriot, 2008; Feola, et al., 2008a; Feola, et al., 2008b; Vidal, 2008; Bonilla, 2009; Bordet, 2009; Clemente, et al., 2009; Kruk, et al., 2009; Feola, et al., 2010; Rodríguez-Gallego, 2010; Steffen e Inda, 2010; Aubriot, et al., 2011; Chalar, et al., 2011a; Chalar, et al., 2011b; Delbene, et al., 2011; DINAMA-JICA, 2011; Feola, et al.,2011a; Feola, et al., 2011b; Ferrari, et al., 2011b; Ferrari, et al., 2011c; Feola, et al., 2012; Somma, 2014) y datos históricos no publicados de OSE, Sección Limnología de la Facultad de Ciencias y de Facultad de Química. Se obtuvo una matriz de 3061 datos georreferenciados para 64 cuerpos de agua superficiales del país (arroyos: 16, ríos: 13, lagos: 11, lagunas: 15, embalses: 8 y playas del Río de la Plata). Los mismos se clasificaron como ambientes lénticos, ecosistema lago, laguna, embalse y remansos de playas (costa), y ambientes lóticos (ecosistema arroyo y río).

Cada dato fue verificado y se relevó el método utilizado con los niveles de detección y cuantificación correspondientes. Se recopiló información disponible de análisis de cianotoxinas (microcistinas desde 1997 y saxitoxinas y cilindrospermopsina desde 2008) realizados ante la presencia de cianobacterias potencialmente tóxicas. En todos los casos se determinaron las toxinas "totales" (intracelular + extracelular), luego del tratamiento de las muestras con tres ciclos de congelado y descongelado. Las microcistinas se analizaron mediante cuatro métodos diferentes: kits de ELISA en placa de producción nacional (límite de cuantificación, $\mathrm{LC}=0,3 \mu \mathrm{gL}^{-1}$ ) (Pírez, et al., 2013) y de Envirologix ( $\left.\mathrm{LC}=0,16 \mu \mathrm{gL}^{-1}\right)$, kits de ELISA en tubos Envirologix (detección en rangos de $<0,5 \mu \mathrm{gL}^{-1}$, entre 0,5 y $\left.3,0 \mu \mathrm{gL}^{-1} \mathrm{y}>3,0 \mu \mathrm{gL}^{-1}\right)$ y HPLC para variedad MC-LR (LC=0,35 $\mu \mathrm{gL}^{-1}$ ) (método ISO 20179:2005). Los análisis de saxitoxinas y cilindrospermopsina fueron realizados mediante kits de ELISA en placa de Abraxis ( $\mathrm{LC}=0,02 \mu \mathrm{gL}^{-1}$ y $0,05 \mu \mathrm{gL}^{-1}$, saxitoxina y cilindrospermopsina, respectivamente).

Los datos de concentración de clorofila $a$ utilizados provienen de diferentes métodos analíticos de rutina en limnología utilizados por las diferentes instituciones, LATU y Facultad de Ciencias (ISO 10260, International Organization for Standarization, 1992) y DINAMA (7004 UY: DINAMA, 2009; APHA, 10200H, APHA et al., 2005). Si bien los métodos presentan diferencias en el límite de detección, se seleccionaron las concentraciones $\geq 1 \mu \mathrm{g} \mathrm{L}^{-1}$ de clo $a$ para la elaboración de los mapas y los análisis estadísticos, ya que es un valor de cuantificación común a todos los métodos. Los valores de células y biovolumen disponibles provenían en todos los casos de análisis que habían seguido procedimientos de rutina en limnología (Sournia, 1978) y, por lo tanto, se consideraron comparables. Los datos no cumplieron con los supuestos de homogeneidad de varianza y normalidad, por lo que se realizaron correlaciones no paramétricas (Spearman) entre las variables y se hicieron análisis no paramétricos (Mann-Whitney y Kruskal - Wallis) para explorar diferencias significativas entre ecosistemas o épocas del año, utilizando el programa SigmaPlot 11 y STATISTICA 8.0. Para probar las relaciones entre la concentración de fósforo total como indicador de estado trófico, la temperatura (efectos fijos e interacción) y la clorofila $a$ como indicador de fitoplancton y cianobacterias (variable biológica con el mayor número de datos) se aplicó un modelo lineal generalizado GLM (con variable de respuesta transformada, Log) para los ecosistemas lénticos y para lóticos. A partir del modelo inicial de efectos fijos e interacciones se eliminaron los términos no significativos comparando el valor del criterio de información de Akaike (AIC). Para este análisis se utilizó el paquete estadístico glm2, programa R (3.0.3.6). Para la elaboración de los mapas, se exportó la matriz de datos a un sistema de información geográfica (ArcGIS 10) donde los sitios están superponderados con una capa de las cuencas hidrográficas y otra de los cursos hídricos del país. Para realizar el primer mapa, cada dato fue clasificado en una categoría según su nivel de riesgo de acuerdo a uno de los tres indicadores globales cuantitativos, cél-C, BV-C o clo $a$, siguiendo las guías de la OMS para aguas recreacionales. Estos tres niveles guía se definen en función de dos valores: baja probabilidad de riesgo, cuando se presentan valores menores al nivel Guía 1 (Guía 1, 20.000 cel mL ${ }^{-1}, 2 \mathrm{~mm}^{3} \mathrm{~L}^{-1}$ y $10 \mu \mathrm{g} \mathrm{L} \mathrm{L}^{-1}$; cél-C, BV-C y clo $a$, respectivamente); riesgo moderado, para datos mayores al nivel Guía 1 y menores al nivel Guía 2 (100.000 cel mL-1, 10 $\mathrm{mm}^{3} \mathrm{~L}^{-1}$ y $50 \mu \mathrm{g} \mathrm{L}^{-1}$; cél-C, BV-C y clo $a$, respectivamente) y riesgo alto, cuando los datos son mayores al nivel Guía 2. Se elaboró un segundo mapa para microcistinas, dado que fue la toxina con mayor número de datos y la única para la que existen valores guía de la OMS. Estos datos se categorizaron según los niveles de la OMS (Chorus y Bartram, 1999) con pequeñas modificaciones (riesgo bajo: 2 a $5 \mu \mathrm{g} \mathrm{L} \mathrm{L}^{-1}$ de microcistina < valor Guía 1; moderado: 5 a $20 \mu \mathrm{g} \mathrm{L}^{-1}$ entre los valores Guía 1 y 2, y alto $>20 \mu \mathrm{g} \mathrm{L}^{-1}$, valor Guía 2).

Complementariamente a la recopilación de datos históricos, se analizaron muestras de agua utilizada como abrevadero para el ganado, con presencia de espuma de cianobacterias en zonas costeras del embalse de Baygorria (15/3/2013). Se determinó la concentración de microcistina en altas biomasas y su correspondencia con genes involucrados en la síntesis de dichas cianotoxinas. Se tomaron con recipiente de boca ancha tres muestras de orilla con densa espuma de cianobacterias, 
para su observación en microscopio y análisis de toxinas. Las muestras para toxinas se congelaron $\left(-20^{\circ} \mathrm{C}\right)$ hasta su análisis. Se determinaron las microcistinas totales (ELISA, kit de Facultad de Química) en dos muestras, procediendo al congelado y descongelado de la muestra en tres ciclos consecutivos para la liberación de la toxina de la célula. Para la extracción de ADN se filtraron 250-300 mL de una muestra con filtros de acetato de celulosa de $0,2 \mu \mathrm{m}$ de tamaño de poro (Zhou, et al., 1996). La calidad del ADN extraído se confirmó por espectrofotometría y luego se almacenó a -20 ${ }^{\circ} \mathrm{C}$ hasta su empleo en el qPCR. Para detectar la presencia de genes que codifican para la síntesis de microcistina $(m c y)$ se usaron primers dirigidos a los genes $m c y B$ (Hautala, et al., 2013) y $m c y J$ (Kim, et al., 2010). Se empleó el kit Power SYBR Green PCR (Invitrogen) con un volumen final de reacción de $20 \mu \mathrm{L}^{-1}$ y un termociclador TouchTM Real-Time PCR Detection System (BIO RAD), con las siguientes condiciones de ciclado: 2 min a $50^{\circ} \mathrm{C}, 15 \mathrm{~min}$ a $95^{\circ} \mathrm{C}$ y 40 ciclos de 15 segundos a $94{ }^{\circ} \mathrm{C}$, 30 segundos a $60^{\circ} \mathrm{C}$ y 30 segundos a $72{ }^{\circ} \mathrm{C}$. Se realizaron curvas de calibración y cuantificación del número de copias génicas empleando los genes blanco clonados en vectores. Para determinar el número de copias se hicieron diluciones seriadas de los genes clonados y se realizó el ajuste de la curva.

\section{Resultados}

\section{Indicadores cuantitativos de cianobacterias}

Se recopilaron datos de ambientes lénticos y lóticos distribuidos irregularmente en las principales cuencas hidrográficas del país desde 1980 hasta $2014(\mathrm{n}=3061)$, mayormente para el período 2007 a 2012 (2275 datos). La mayoría correspondieron a costas y playas del Río de la Plata o de grandes ríos ( $\mathrm{n}=993)$, seguidos de ríos (822), embalses (779), lagunas (288), arroyos (114) y lagos (64). La mayor cantidad de datos correspondió a ambientes lénticos $(\mathrm{n}=2121)$ y a períodos estivales $(n=1439)$.

Del total de datos con al menos un indicador biológico de fitoplancton, la mayoría correspondió a la concentración de clo $a(\mathrm{n}=2387)$, seguida de BV-C (472) y cél-C (356). Los tres indicadores estuvieron altamente correlacionados entre sí (clo $a$ - cél-C, $\mathrm{p}=0,44, \mathrm{p}<0,001$, clo $a-\mathrm{BV}-\mathrm{C}, \mathrm{p}=0,54$, $\mathrm{p}$ $<0,001$ y cél-C - BV-C, p =0,91, p < 0,001) y co-ocurrieron solamente en 88 casos. Las cél-C variaron ampliamente des-

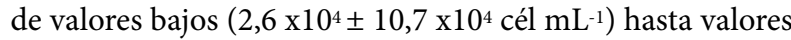
correspondientes a espuma de cianobacterias, usualmente acumuladas en las orillas de playas con cél-C hasta cinco órdenes de magnitud más altos $\left(1407 \times 10^{6} \pm 4419 \times 10^{6}\right.$ cél $\mathrm{mL}^{-1}$ ), mientras que el valor promedio de BV-C fue de 8,37 $\mathrm{mm}^{3} \mathrm{~L}^{-1}\left( \pm 20,84 \mathrm{~mm}^{3} \mathrm{~L}^{-1}\right)$ y solo se registró un valor de BV-C en presencia de espuma $\left(35,4 \mathrm{~mm}^{3} \mathrm{~L}^{-1}\right)$. La concentración de la clo $a$ tuvo un valor promedio de $13 \mu \mathrm{g} \mathrm{L}^{-1}( \pm 22 \mu \mathrm{g} \mathrm{L}-1)$ en ausencia de espuma.

\section{Factores ambientales}

La temperatura del agua, para la cual se registró la presencia de cianobacterias, varió en un amplio rango, desde $7{ }^{\circ} \mathrm{C}$ a $36^{\circ} \mathrm{C}$ y los ambientes lénticos alcanzaron en general las mayores temperaturas (Tabla 1 ). La clo a como indicador cuantitativo a valores de riesgo moderado $\left(10-50 \mu \mathrm{g} \mathrm{L}^{-1}\right)$ y alto $\left(>50 \mu \mathrm{g} \mathrm{L}^{-1}\right)$ de exposición a cianobacterias se registró en un amplio rango de temperaturas $\left(7\right.$ a $36^{\circ} \mathrm{C}$ y 11 a $35^{\circ} \mathrm{C}$, para riesgo moderado y alto, respectivamente). La concentración de los nutrientes totales (nitrógeno y fósforo totales) fue significativamente más alta en los ambientes lóticos con respecto a los lénticos (Kruskall-Wallis, $\mathrm{p}<$ 0,05) (Tabla 1). Por el contrario, la concentración de clo $a$, cél-C y BV-C fue significativamente mayor en los ambientes lénticos con respecto a los lóticos (Kruskall-Wallis, $\mathrm{p}<0,05)$ (Tabla 1). En los ecosistemas lénticos el PT y la temperatura y la interacción de ambas, explicaron el $22 \%$ de la deviancia de la clo $a$ (GLM). Sin embargo, para los ecosistemas lóticos el PT y la temperatura (sin interacción) solamente explicaron el $5 \%$ de la deviancia de la clo $a$. Los ecosistemas que registraron mayores valores de clo $a$ fueron los lagos y los remansos de costa de embalses, ríos y arroyos (ej. playas) (Figura 1). En los lagos, la mayoría de los valores estuvieron por encima del nivel Guía 2 de la OMS. En el resto de los ecosistemas, se registraron generalmente valores por debajo del nivel Guía 1 (Figura 1). Las concentraciones de clo a fueron significativamente más altas en el verano en comparación con las otras épocas del año $(p<0,05)$, aunque se observaron valores por encima de los niveles Guía 1 y 2 en todo el año (Figura 1). En los ambientes lénticos se registraron espumas, con valores de clo a mayores al miligramo por litro en playas de Montevideo (2006 y 2008: de 12,0 a 37,8 $\mathrm{mg} \mathrm{L}^{-1}$ ) y del embalse de Baygorria, Río Negro (2014: $51 \mathrm{mg} \mathrm{L}^{-1}$ ).

\section{Concentración de cianotoxinas}

Los registros de cianotoxinas comienzan en 1997 y del total de datos se analizaron cianotoxinas en 651 muestras. La cianotoxina reportada con mayor frecuencia fue la microcistina $(n=342)$. Las concentraciones de cianotoxinas más elevadas fueron registradas para las microcistinas y las más bajas para cilindrospermopsinas (Tabla 2).

\begin{tabular}{|c|c|c|c|c|}
\hline Ambiente & Temperatura $\left({ }^{\circ} \mathrm{C}\right)$ & Nitrógeno total $\left(\mathrm{mg} \mathrm{L}^{-1}\right)$ & Fósforo total $\left(\mu \mathrm{g} \mathrm{L}^{-1}\right)$ & Clo $a\left(\mu \mathrm{g} \mathrm{L}^{-1}\right)$ \\
\hline \multirow{2}{*}{ Lótico } & $22(7-29)$ & $1(0,1-54)$ & $75(11-5490)$ & $3,5(1-185)$ \\
& 420 & 358 & 383 & 421 \\
Léntico & $24(9-36)$ & $0,6(0,005-53)$ & $69(5-1077)$ & $7(1-50.912)$ \\
& 1244 & 465 & 520 & 1946 \\
\hline
\end{tabular}

Tabla 1. Valores de temperatura, nitrógeno y fósforo totales y clorofila $a$ fitoplanctónica (clo $a$ ) por tipo de ambiente (lótico y léntico). Se indica mediana, mínimos y máximos entre paréntesis y número de datos (cursiva) para cada variable. 


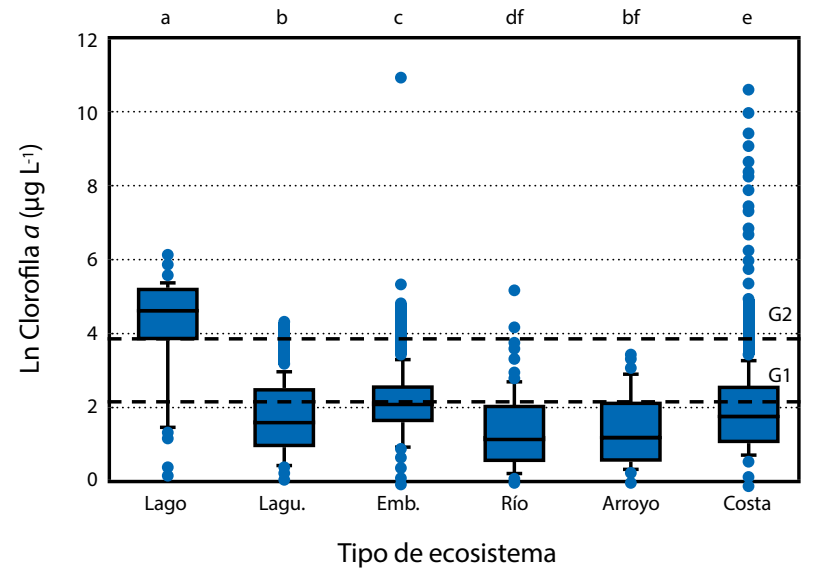

B

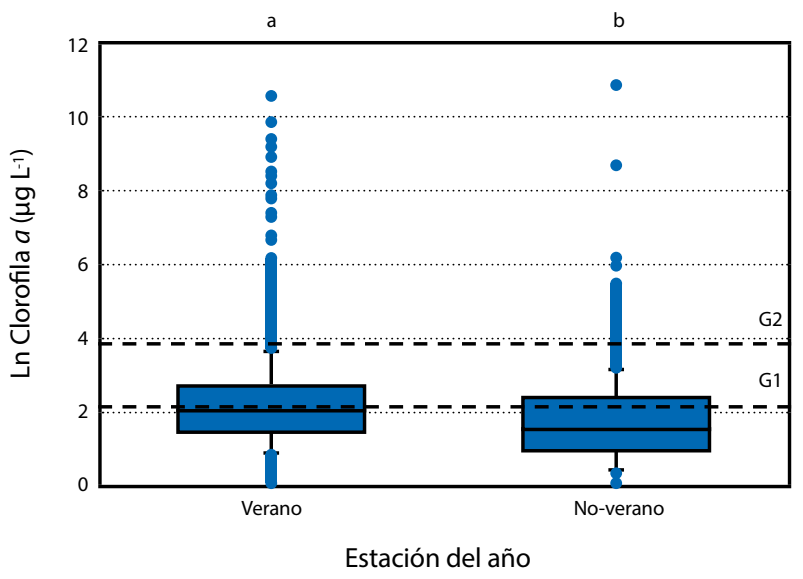

C

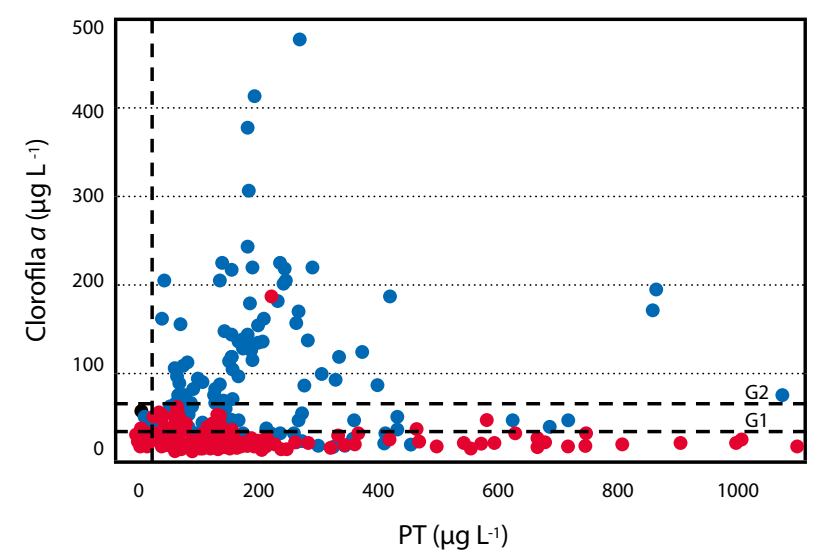

Figura 1. A: Concentración de clo a según tipo de ecosistema y B: época del año, discriminado en período estival (verano) y el resto del año (no verano). Límite superior e inferior de las cajas: percentil 75 y 25, respectivamente, línea continua horizontal: mediana, líneas verticales arriba y abajo: percentil 90 y 10, respectivamente, y círculos azules: valores atípicos. Las líneas punteadas horizontales indican los límites de los niveles Guía 1 y 2 (G1 y G2, respectivamente) de la OMS para aguas recreacionales. Las letras diferentes indican diferencias significativas ( $\mathrm{p}<0,05)$. C: relación entre la clo $a\left(1\right.$ a $\left.500 \mu \mathrm{g} \mathrm{L} \mathrm{L}^{-1}\right)$ y el fósforo total (PT) discriminado según tipo de ecosistema (léntico, círculos azules y lótico, círculos rojos). La línea vertical indica el límite de PT de estándar de calidad de agua según la legislación uruguaya $\left(25 \mu \mathrm{g} \mathrm{L} \mathrm{L}^{-1}\right)$.

El valor máximo de microcistinas totales $\left(38 \mathrm{mg} \mathrm{L}^{-1}\right)$ se registró en condiciones de concentración de clo $a>200 \mu \mathrm{g} \mathrm{L}-1$ (Tabla 2), proveniente de una muestra de espuma de cianobacterias en el embalse Baygorria (Río Negro) de 2014. Los mayores valores de microcistinas se registraron en lagos (Kruskall Wallis, $\mathrm{p}<0,05$ ), seguido de embalses y costas, muchas veces superando los niveles Guía 1 y 2 (Tabla 2, Figura 3). Por otro lado, los valores más altos para saxitoxina (STX) se reportaron en lagos $(\mathrm{p}<0,05)$ y para cilindrospermopsina (CIL) no se encontraron diferencias significativas en la concentración entre los distintos tipos de ecosistema.

Se registraron concentraciones significativamente más altas de microcistinas en el período estival en comparación con el resto del año (no verano) $(\mathrm{p}<0,05)$, mientras que no se registraron diferencias entre épocas del año para las otras cianotoxinas.

\begin{tabular}{|c|c|}
\hline Cianotoxinas & Mediana (Mínimo - Máximo), $n$ \\
\hline MYC $\left(<200 \mu \mathrm{g} \mathrm{L}^{-1}\right)$ & $0,6(<0,16-25), 314$ \\
$\mathrm{MYC}\left(>200 \mu \mathrm{g} \mathrm{L}^{-1}\right)$ & $1478(250-38.000), 31$ \\
$\mathrm{STX}\left(\mu \mathrm{g} \mathrm{L}^{-1}\right)$ & $1,74(<0,02-14,62), 18$ \\
$\mathrm{CIL}\left(\mu \mathrm{g} \mathrm{L}^{-1}\right)$ & $0,08(<0,05-0,12), 13$ \\
\hline
\end{tabular}

Tabla 2. Concentraciones de cianotoxinas determinadas (mediante ELISA y HPLC) en cuerpos de agua continentales del país: microcistinas (MYC), saxitoxinas (STX) y cilindrospermopsina (CIL). Se indica la mediana, mínimos y máximos entre paréntesis y número de datos (n). 


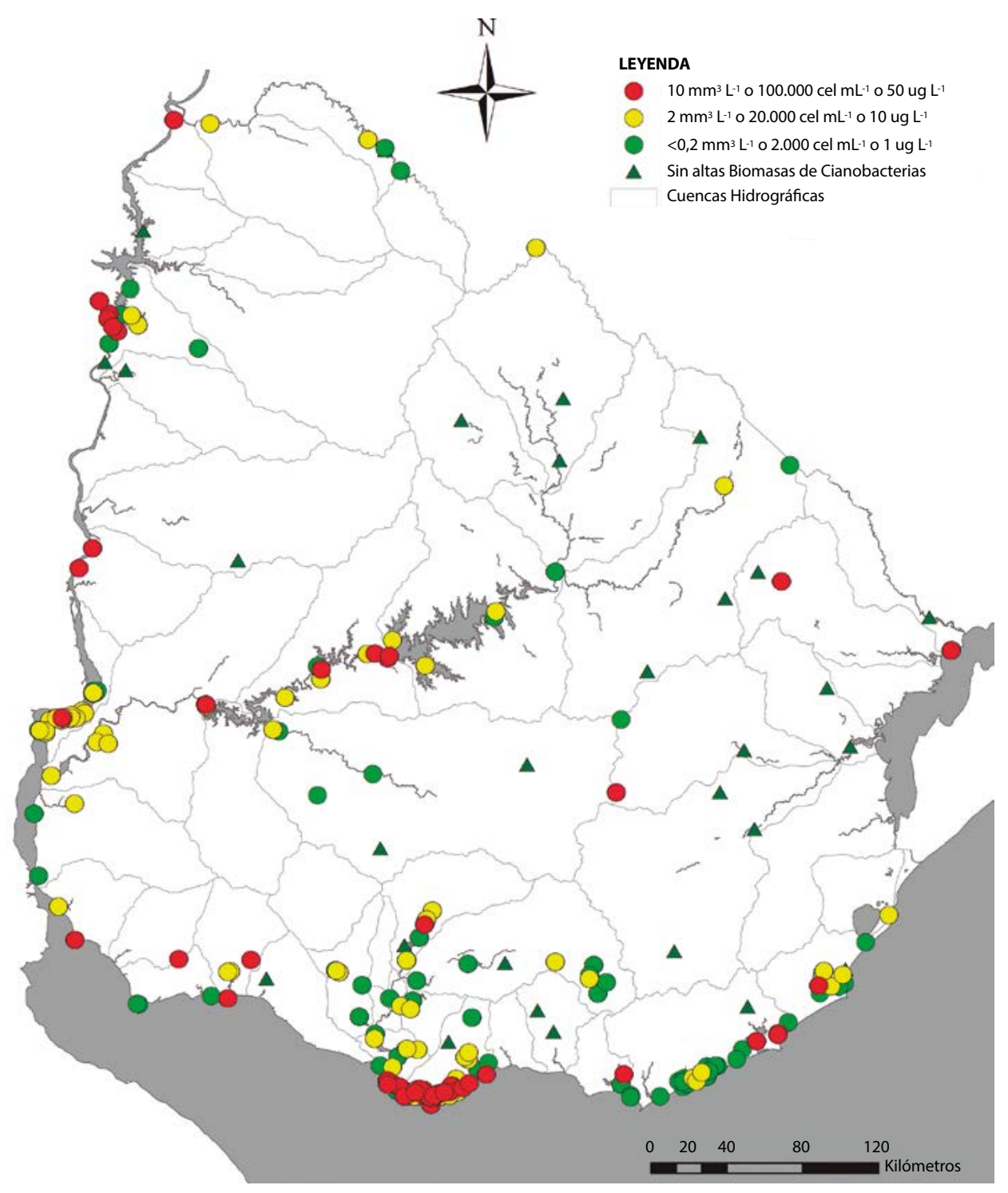

Figura 2. Mapa de Uruguay con los sitios georreferenciados donde se han detectado cianobacterias (1980-2014), categorizados según los niveles guía de la OMS para aguas recreacionales en base a los indicadores globales (BV-C, cél-C o clo $a$ ) y datos cualitativos. Círculos amarillos = riesgo bajo, círculos verdes = riesgo moderado, círculos rojos = riesgo alto (por encima del nivel Guía 2), triángulos verde oscuro = sin eventos de cianobacterias (2008 - 2012, datos cualitativos OSE).

\section{Evaluación del riesgo para aguas recreativas}

La distribución de cianobacterias en el mapa del país permitió visualizar regiones con peligrosidad moderada de exposición a cianobacterias (entre los niveles Guía 1 y 2 ) y alta (por encima del nivel Guía 2), generalmente asociado a zonas embalsadas de los grandes ríos (Uruguay y Río Negro), zonas costeras (Río de la Plata) y lagos o lagunas (Figura 2). La mayoría de los sitios tienen actividades recreativas, particularmente en las costas de Río de la Plata, Río Negro y Río Uruguay. El mapa permitió además identificar vacíos de información, en particular en la zona noroeste del país (Figura 2). Se destacan además algunos puntos con riesgo moderado o alto en ecosistemas lóticos (Figura 2). El mapa de distribución de microcistinas (Figura 3) fue coherente con el mapa basado en indicadores cuantitativos en la mayoría de los casos (Figura 2), indicando zonas de mayor riesgo (Alto) en embalses de Río Negro y en zonas costeras del Río de la Plata (Figura 3).

\section{Estudio de caso: microcistinas en embalse Baygorria}

De los análisis realizados en este trabajo con muestras del embalse de Baygorria, con presencia de espuma (15/3/2013), se determinó la dominancia de Microcystis spp. y se registraron $20,04 \mathrm{mg} \mathrm{L}^{-1}\left( \pm 1,6 \mathrm{mg} \mathrm{L}^{-1}\right)$ de microcistinas totales (ELISA). La presencia y abundancia relativa de dos genes pertenecientes al cluster $m c y$ se determinó por qPCR y se encontraron altas abundancias tanto de $m c y B\left(1,98 \times 10^{4}\right.$ copias/ng ADN $)$ como de $m c y J\left(1,40 \times 10^{5}\right.$ copias/ng ADN), pero con diferencias significativas entre ambos $(m c y B<m c y J$, $\mathrm{p}<0,05)$. 


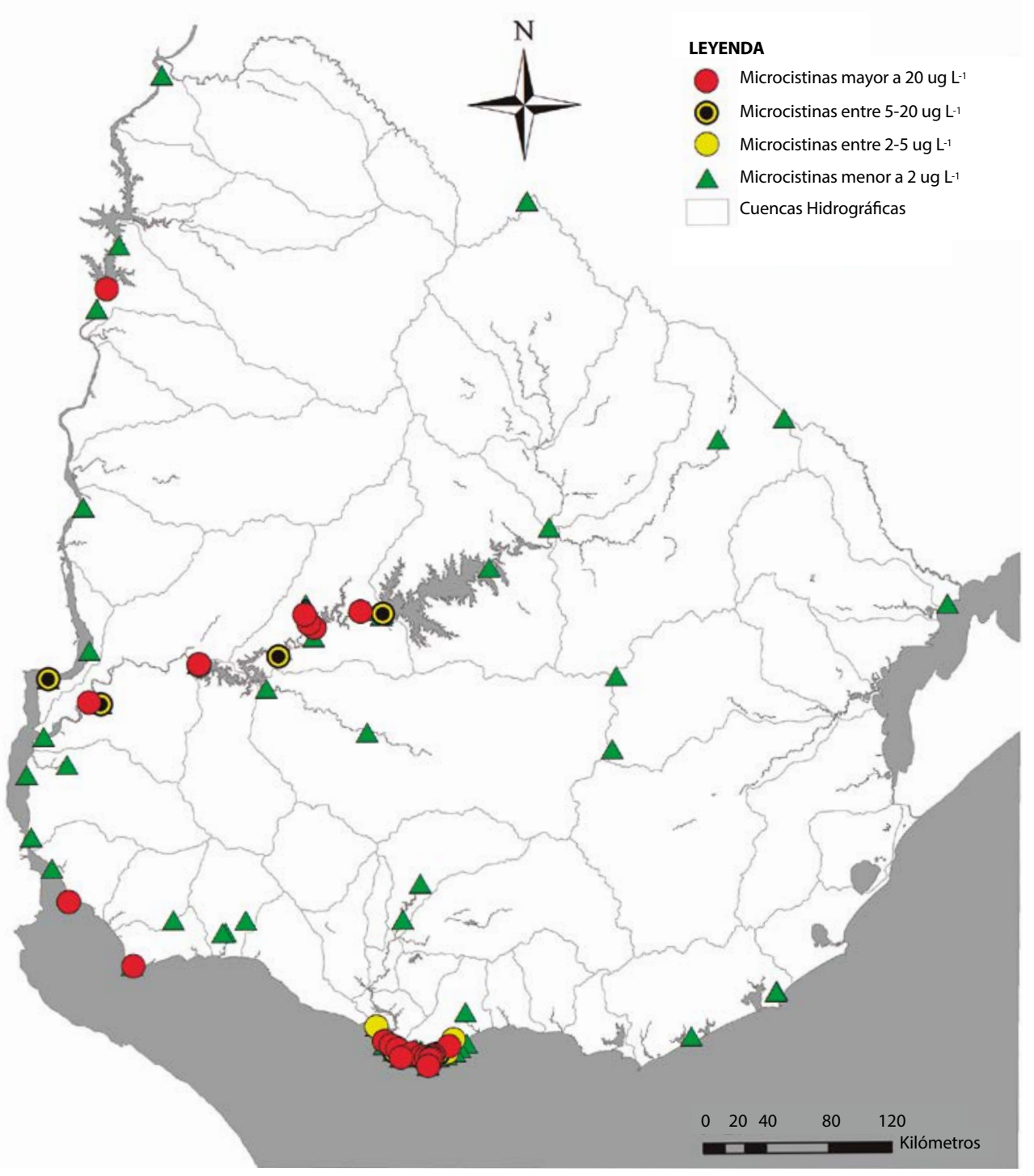

Figura 3. Mapa de Uruguay con los sitios georreferenciados donde se han detectado microcistinas (1997 - 2014), categorizados según los niveles guía de la OMS para aguas recreacionales. Triángulos verdes y círculos amarillos = riesgo bajo < nivel Guía 1, círculos amarillos con punto negro = riesgo moderado, entre el nivel Guía 1 y 2 y círculos rojos $=$ riesgo alto $>$ nivel Guía 2 .

\section{Discusión}

En este trabajo se resume y analiza información de cuerpos de agua del país sobre la presencia y riesgo potencial de exposición a cianobacterias y las principales cianotoxinas. Incluye información técnica y científica y cuenta con la participación de cuatro instituciones públicas, lo que permitió generar una base de datos sobre cianobacterias e indicadores de calidad de agua a nivel país, con más de 30 años de información disponible. Se elaboraron mapas georreferenciados que permiten visualizar claramente regiones con mayor o menor riesgo de presencia de cianobacterias. Además, estos mapas pueden servir como punto de partida para otros estudios más profundos o para evaluar posibles cambios de la situación a lo largo del tiempo.

\section{Distribución espacial de floraciones de cianobacterias en el país}

El mapa de categorización de los cuerpos de agua del país permitió identificar zonas de mayor peligrosidad de exposición a las cianobacterias. En particular las zonas embalsadas de los grandes ríos como el Río Uruguay y el Río Negro y las costas del Río de la Plata fueron los ecosistemas con mayores registros de riesgo de exposición alto, con acumulación de espuma de cianobacterias, en concordancia con trabajos anteriores publicados para estos ecosistemas (De León y Yunes, 2001; González-Piana, et al., 2011; O'Farrell, et al., 2012; Pírez, et al., 2013). Los primeros registros de floraciones de cianobacterias para el país fueron en el embalse de Salto Grande, Río Uruguay, en 1980 (Quirós y Luchini, 1982), ambiente que ha tenido recurrentes registros de floraciones de cianobacterias 
a lo largo de décadas (Chalar, et al., 2002; Giannuzzi, et al., 2011). En Baygorria (2014), con presencia de espuma de cianobacterias, se reportaron los valores de clo $a$ fitoplanctónica más altos registrados hasta la fecha para el país. Las floraciones de cianobacterias acumulativas generalmente forman gruesas capas en la superficie del agua (espuma) gracias a la regulación de la flotación vía las vacuolas de gas intracelulares (Oliver y Ganf, 2000) y la acumulación en playas o zonas someras por el viento (Chorus y Bartram, 1999). Las espumas que se acumulan en las orillas de playas y remansos configuran un riesgo máximo de exposición a cianotoxinas u otros problemas sanitarios para los potenciales usuarios del cuerpo de agua, principalmente en el período estival.

Indicadores de alto riesgo de exposición a cianobacterias ocurrieron tanto en verano como en otras épocas del año, sugiriendo que la temperatura no es necesariamente una variable que limite el crecimiento y la acumulación de estos organismos en Uruguay. La temperatura es una variable clave para explicar el crecimiento del fitoplancton en general y su papel predictivo de la presencia de cianobacterias varía según se trate de ecosistemas templados o subtropicales y el estado trófico de los mismos (Rigosi, et al., 2014; Mowe, et al., 2015). Por otro lado, los efectos del cambio climático pueden actuar en sinergia con el aumento de los nutrientes, acelerando la eutrofización (Meerhoff, et al., 2007; Moss, et al., 2011) y promoviendo la aparición de floraciones de cianobacterias (O'Neil, et al., 2012), como se ha demostrado en un estudio de largo plazo (1991 - 2010) para el lago Taihu, China, afectado por densas floraciones de Microcystis (Deng, et al., 2014). Por lo tanto, sería recomendable que los programas de monitoreo de calidad de agua en Uruguay incluyeran la temperatura como variable indicadora junto con variables cuantitativas de fitoplancton y cianobacterias. Para diseñar programas de monitoreo, se destaca la necesidad de considerar todo el ciclo anual, ya que fuera del período estival pueden registrarse eventos de floraciones de cianobacterias, lo que puede tender a aumentar con los efectos a largo plazo del cambio climático.

\section{Eutrofización y cianobacterias}

Los resultados de este trabajo evidencian la condición eutrófica de varios tipos de los ecosistemas estudiados. La eutrofización en cuerpos de agua de Uruguay es una problemática que tiene varias décadas y está asociada al uso del suelo en la cuenca y a cambios hidrológicos artificiales (Quirós y Luchini, 1982; Conde y Sommaruga, 1999; Conde, et al., 2002; Aubriot, et al., 2005), afectando muchas veces cuerpos de agua destinados a usos múltiples o la potabilización (Mazzeo, et al., 1993 y 2003; Arocena, et al., 2008; compilación en: Bonilla y Meerhoff, 2014). Los valores registrados en este estudio indican que los ecosistemas lóticos tienen una mayor disponibilidad de nutrientes, pero que el crecimiento del fitoplancton está limitado por otros factores. Las diferencias en el funcionamiento de ríos y de lagos (Moss, 1998) hace que bajo concentraciones similares de nutrientes, los ríos presenten una menor productividad primaria fitoplanctónica respecto a los lagos (Moss, 1998), lo que se refleja en los rangos tróficos (resumidos por Smith y colaboradores, 1999). Mientras que el rango eutrófico en ríos se caracteriza por valores de clo $a$ de 10 a $30 \mu \mathrm{g} \mathrm{L}^{-1}$ y fósforo total $>75 \mu \mathrm{g} \mathrm{L}^{-1}$, en los lagos comienza con valores de clo a entre 9 a $25 \mu \mathrm{g} \mathrm{L}^{-1}$ y fósforo total $>30 \mu \mathrm{g} \mathrm{L}^{-1}$ (hasta $100 \mu \mathrm{g} \mathrm{L}^{-1}$ ) (Smith, et al., 1999). Lo mismo ocurre para las concentraciones de nitrógeno total de sistemas eutróficos (NT > 1,5 mg L-1 y de 0,7 a 1,2 $\mathrm{mg} \mathrm{L}^{-1}$, para ríos y lagos, respectivamente) (Smith, et al., 1999). Por lo tanto, para la base de datos de nuestro estudio, estos indicadores sugieren que muchos ambientes están cercanos a la eutrofia o a la hipereutrofia. La legislación uruguaya vigente sobre clases de agua establece que el estándar permitido de concentración de fósforo total es $25 \mu \mathrm{g}$ PT L-1, para todas las clases de agua, Decreto 253/79 (Uruguay, 1979), y por lo tanto la mayor parte de los ecosistemas acuáticos analizados en este estudio están por encima de dicho valor, en algunos casos hasta dos órdenes de magnitud. En un escenario de cambio climático y eutrofización, la reducción de la carga de nutrientes sigue siendo un aspecto clave a la hora de recuperar ecosistemas afectados por floraciones de cianobacterias (Moss, et al., 2011; O'Neil, et al., 2012).

Uno de los factores más importantes que favorece el crecimiento del fitoplancton y de las cianobacterias en ecosistemas lóticos es el incremento del tiempo de residencia del agua, que ocurre, por ejemplo, en la construcción de embalses (Rangel, et al., 2012; Paerl y Otten, 2013). Trabajos recientes atribuyen las floraciones frecuentes de Microcystis y Dolichospermum en el embalse de Salto Grande (Río Uruguay) a los altos tiempos de residencia en los brazos del embalse y morfometría dendrítica del mismo (O'Farrell, et al., 2012). Es por esto que las modificaciones artificiales que puedan realizarse afectando la hidrología en ambientes lóticos con alta carga de nutrientes pueden ser decisivas para promover floraciones de cianobacterias potencialmente tóxicas.

\section{Cianotoxinas: distribución y tipos}

La microcistina fue la cianotoxina que presentó mayores concentraciones, mayor distribución en el país y mayor frecuencia de aparición. Los primeros reportes de esta cianotoxina en el país corresponden a zonas de costa del Río de la Plata (Colonia, 1991) (De León y Yunes, 2001) y son recurrentes en playas y remansos de ríos o embalses (González-Piana, et al., 2011; Pírez, et al., 2013). En el embalse de Salto Grande se registró un caso de intoxicación aguda grave en humanos (Giannuzzi, et al., 2011). Esta cianotoxina es la más frecuente en las floraciones de cianobacterias en el mundo entero, tanto en regiones templadas como tropicales (van Apeldoorn, et al., 2007; Mowe, et al., 2015). Las microcistinas son también las cianotoxinas más reportadas en los países de la región, lo que también se relaciona a su frecuencia de aparición y las capacidades analíticas (Sant'Anna, et al., 2008; Echenique y Aguilera, 2009). La saxitoxina y cilindrospermopsina han sido menos analizadas en nuestro país que la microcistina. Esto puede deberse a las limitaciones analíticas para su determinación, ya que en el país solo se pueden determinar con kits comerciales de ELISA. Las saxitoxinas y la cilindrospermopsina son menos frecuentes que la microcistina en la naturaleza (van Apeldoorn, et al., 2007) y debido a la falta de datos toxicológicos no hay valores guía recomendados por la OMS para las mismas, tanto para aguas de recreación como para potabilización (Chorus, 2012). Sin embargo, algunos países han incorporado recientemente valores guía de estas toxinas para agua potable, como Australia (STX $=3,0 \mu \mathrm{g} \mathrm{L}^{-1}$ y CIL $\left.=1,0 \mu \mathrm{g} \mathrm{L}^{-1}\right)$, Brasil $\left(\mathrm{STX}=3,0 \mu \mathrm{g} \mathrm{L}^{-1}\right.$ y CIL $\left.=15 \mu \mathrm{g} \mathrm{L}^{-1}\right)$ y Nueva Zelanda (STX $=3,0 \mu \mathrm{g} \mathrm{L}^{-1}$ y CIL $=1 \mu \mathrm{g} \mathrm{L}^{-1}$ ) (Chorus, 2012; Brasil, 2011). Para aguas recreacionales la única legislación (Oregon, EEUU) que presenta valores de referencia para STX establece $100 \mu \mathrm{g} \mathrm{L}^{-1}$ como máximo. 
La correlación entre la concentración de cianotoxinas y biomasa de cianobacterias no siempre es clara (Oliver y Ganf, 2000), por lo que la OMS recomienda realizar análisis cuantitativos de toxinas según los valores de biomasa encontrados en la muestra (Chorus y Bartram, 1999). Por lo tanto, la incorporación de análisis cuantitativos de cianotoxinas o de la presencia de genes de cianotoxinas en muestras de programas de monitoreo podría mejorar la capacidad de alerta y de mitigación en la gestión de los recursos hídricos del país.

Las muestras analizadas de espumas de cianobacterias del embalse Baygorria permitieron determinar las mayores concentraciones de microcistina registradas hasta el presente para el país (embalse Baygorria, 2013) que fueron 100 veces mayores que el límite de $20 \mu \mathrm{g} \mathrm{L}^{-1}$ de microcistina-LR propuesto por la OMS para riesgo alto (Chorus y Bartram, 1999). En estudios anteriores se reportaron altas concentraciones de microcistina-LR en floraciones de Microcystis aeruginosa para los embalses del Río Negro, Bonete (2,0 mg $\left.\mathrm{L}^{-1}\right)$, Baygorria $\left(0,5 \mathrm{mg} \mathrm{L}^{-1}\right)$ y Palmar $\left(2,6 \mathrm{mg} \mathrm{L}^{-1}\right)$ en verano de 2010 (González-Piana, et al., 2011), uno a dos órdenes de magnitud más bajas que los valores máximos encontrados en este estudio (embalse Bayorria, 2013). En el estudio genético en la muestra de Baygorria, la detección de altos números de copias por unidad de biomasa de los genes $m c y B$ y $m c y J$ no resulta sorprendente dada la concentración de microcistinas detectadas en la muestra, si bien es llamativa la diferencia de un orden de magnitud entre la abundancia relativa de ambos genes $(m c y B<m c y J)$. Esto podría explicarse por la existencia de variabilidad natural en la secuencia del cluster $m c y$ debido a mutaciones, recombinaciones y presencia de transposasas a nivel de $m c y B$ (Kurmayer y Gumpenberger, 2006). Se ha demostrado que eventos de recombinación entre el dominio de adenilación $m c y B 1$ de $m c y B$ y el dominio correspondiente en otro gen, $m c y C$, da lugar a distintas isoformas de microcistina. Por ende, los resultados obtenidos del gen mcyJ en nuestro estudio indican la abundancia total de genotipos $m c y$ en la muestra, mientras que la de $m c y B$ sugiere la existencia de otra variedad de microcistina que podría ser más o menos tóxica que la variedad LR. Actualmente no hay información suficiente para poder asociar una floración con la variedad de microcistina presente y depende de la diversidad genética de la muestra (de Figuereido, et al., 2004). Es por esta razón que los análisis genéticos pueden ser una herramienta complementaria a otros análisis cuantitativos para evidenciar la diversidad potencial de diferentes variedades de cianotoxinas.

\section{Indicadores cuantitativos de cianobacterias y monitoreo}

Los indicadores cuantitativos de riesgo de exposición a cianobacterias presentaron gran disparidad en el número de datos disponible. La clo $a$ fitoplanctónica fue el indicador más ampliamente utilizado en programas de monitoreo y trabajos de investigación en el país y el número de células de cianobacterias el menos utilizado. Sin embargo, la clo $a$ es un indicador global del fitoplancton y, por lo tanto, indirecto sobre la peligrosidad potencial de la cianobacterias (Chorus y Bartram, 1999). De un total de de 18 países con legislaciones para aguas recreacionales, en la mayoría se utiliza la observación visual (presencia o ausencia de cianobacterias a simple vista) o la concentración de la clo a como variable cuantitativa, seguida de la abundancia de cianobacterias totales y, por último, el biovolumen de cianobacterias (Chorus, 2012). De acuerdo a estudios recientes (Agha, et al., 2012) y a nuestros resultados, el monitoreo de cianobacterias debe adecuarse al tipo de cianobacteria y floración más frecuente (acumulativa o dispersiva) e integrar diferentes escalas de medición. Por ejemplo, la observación visual puede ser una excelente herramienta a incorporar en programas de monitoreo para aquellos ecosistemas que presenten floraciones de cianobacterias acumulativas (visibles a simple vista). La Intendencia de Montevideo lleva adelante un programa de monitoreo de playas con observación visual y el uso de una bandera sanitaria. No obstante, este método no se aplica en ecosistemas con floraciones dispersivas, poco evidentes a simple vista. El monitoreo de cianobacterias debe considerar la biología de los organismos y debe, además, integrar varios indicadores en simultáneo. La OMS recomienda utilizar varios indicadores, por lo que el número de células, el biovolumen y la concentración de cianotoxinas deberían ser utilizados, si bien requieren de personal altamente calificado e insumen mucho tiempo de análisis. La concentración de toxinas puede variar con el ciclo celular, los factores ambientales (Zurawell, et al., 2005) y la cepa, por lo que la correlación entre la concentración de cianotoxinas y la biomasa de cianobacterias no es muy clara (Oliver y Ganf, 2000). Sin embargo, en algunos ecosistemas se han encontrado correlaciones positivas entre la concentración de microcistina y el biovolumen de cianobacterias, como por ejemplo en un estudio reciente en el Río Uruguay (Vidal, et al., 2015). OSE sigue un protocolo interno con diferentes niveles de alerta (Vigilancia, Alerta 1, Alerta 2 y Alerta 3) según el biovolumen de cianobacterias potencialmente tóxicas y la concentración de microcistinas, los que se asocian a diferentes medidas de acción (frecuencias de monitoreo y comunicación a las autoridades correspondientes) (Vidal, et al., 2015).

El uso de la combinación de métodos analíticos, incorporando el estudio de la presencia de genes de cianotoxinas junto con la cuantificación de toxinas y estimación del biovolumen de cianobacterias, permitiría lograr un alcance más confiable para analizar muestras de programas de monitoreo y, por ende, para la gestión de los recursos hídricos del país. A su vez, podría ser útil incorporar otros indicadores cuantitativos de cianobacterias en los programas de monitoreo del país, tanto para agua a potabilizar como para agua destinada a la recreación, como indicadores estimados en tiempo real (pigmentos in vivo) (Cremella, et al., 2015), sumado a la observación visual según el caso. Esto podría contribuir a generar un sistema de alerta de floraciones a nivel país, con información unificada y facilitar la divulgación a la población.

\section{Conclusiones}

La mayor cantidad de datos de la matriz generada en este trabajo fueron posteriores al año 2007, lo que puede reflejar la mayor disponibilidad de informes técnicos de libre acceso, mayor nivel académico y número de investigadores activos formados en temas ambientales, así como un mayor compromiso de parte de los entes públicos responsables de la calidad de agua en la última década.

La puesta a punto de metodologías intercomparables y la selección de algunas variables cuantitativas comunes podrían mejorar la información obtenida y optimizar la gestión de los recursos hídricos del país. Los SIG son una herramienta muy útil a la hora de integrar información espacial de esta 
problemática, permitiendo visualizar rápidamente regiones con situaciones contrastantes y vacíos de información. Los mapas pueden ser actualizados con alta frecuencia o en forma continua, convirtiéndose en una herramienta que puede mejorar el monitoreo de los cuerpos de agua del país. Se espera que este trabajo sea de utilidad para enfatizar la severidad de la problemática de las floraciones de cianobacterias en Uruguay y que contribuya a reforzar la toma de medidas preventivas o de mitigación a la exposición a las cianobacterias en el corto y en mediano plazo, con acciones integradas entre todos los actores responsables del estudio y gestión de los recursos hídricos continentales del país.

\section{Reconocimientos}

A D. Conde, B. Cremella, J. P. Pacheco, L. Reolón, L. Rodríguez-Gallego y G. Yorda por el aporte de datos y a G. Echegoyen por el aporte de muestras. A las autoridades de las instituciones por facilitar el trabajo del equipo técnico. Financiamiento: ANII (FCE-6384), DINAMA, OSE y Universidad de la República.

\section{Referencias}

Agha, R., Cires, S., Wörmer, L., Domínguez, J.A. y Quesada, A., 2012. Multi-scale strategies for the monitoring of freshwater cyanobacteria: Reducing the sources of uncertainty. En: Water Research, 46(9), pp.3043-3053.

APHA, AWWA, WEF, 2005. Standard methods for the examination of water and wastewater. 21a ed. Washington: APHA. Standard Method $10200 \mathrm{H}$.

Arocena, R., Chalar, G., Fabián, D., De León, L., Brugnoli, E., Silva, M., Rodó, E., Machado, I., Pacheco, J. P., Castiglioni, R. y Gabito, L., 2008. Evaluación ecológica de cursos de agua y biomonitoreo. Cuenca Santa Lucía. Montevideo: DINAMA; Facultad de Ciencias, Sección Limnología, Universidad de la República. (Informe inédito).

Aubriot, L., 2008. Flexibilidad de la cinética de incorporación de fosfato por fitoplancton a las fluctuaciones en el suministro del nutriente. Montevideo: PEDECIBA Biología, Facultad de Ciencias, Universidad de la República. (Tesis de Doctorado).

Aubriot, L., Conde, D., Bonilla, S., Hein, V. y Britos, A., 2005. Vulnerabilidad de una laguna costera en una reserva de biosfera: indicios recientes de eutrofización. En: Vila, I. y J. Pizarro (eds.). Taller internacional de eutrofización de lagos y embalses. Montevideo: CYTED XVIIB. pp.65-85.

Aubriot, L., Bonilla, S. y Falkner, G., 2011. Adaptive phosphate uptake behaviour of phytoplankton in response to environmental phosphate fluctuations. En: FEMS Microbiology Ecology, 77(1), pp.1-16.

Aubriot, L. y Bonilla, S., 2012. Rapid regulation of phosphate uptake in freshwater cyanobacterial blooms. En: Aquatic Microbial Ecology, 67(3), pp.251-263.

Boccardi, L., Clemente, J., Dabezies, M., Ferrari, G. y Saizar, C. 2007. Estudio de las comunidades de fitoplancton, zooplancton y macrozoobentos en el tramo inferior del Río Uruguay (Nuevo Berlín, Fray Bentos y Las Cañas). Montevideo: LATU. (Informe de asesoramiento, $\mathrm{N}^{\circ}$ 952512).
Bonilla, S., 2002. Estructura y productividad de la comunidad de microalgas del ambiente pelágico en la Laguna de Rocha. Montevideo: Programa PEDECIBA Biología, Facultad de Ciencias, Universidad de la República. (Tesis de doctorado).

Bonilla, S., 2009. Cianobacterias planctónicas del Uruguay. Manual para la identificación y medidas de monitoreo. Montevideo: UNESCO. PHI-VII (Documento técnico, 16). ISBN: 978-92-9089-138-3.

Bonilla, S., Pérez, M. y De León, L., 1995. Cianofíceas Planctónicas del Lago Ton-Ton, Canelones, Uruguay. En: Hoehnea, 21, pp.85-192.

Bonilla, S. y Conde, D., 2000. El fitoplancton como descriptor sensible de cambios ambientales en las lagunas costeras de la Reserva Bañados del Este. En: Seminario-Taller sobre monitoreo ambiental. Rocha: PROBIDES/UNESCO. (Documentos de Trabajo, N ${ }^{\circ} 31$ ). pp.63-74.

Bonilla, S., Conde, D., Aubriot, L. y Pérez, M. C., 2005. Influence of hydrology on phytoplankton species composition and life strategies in a subtropical coastal lagoon periodically connected with the Atlantic Ocean. En: Estuaries, 28(6), pp.884-895.

Bonilla, S., Conde, D., Aubriot, L., Rodriguez-Gallego, L., Piccini, C., Meerhoff, E., Rodríguez, L., Gómez, P. y Machado, I., 2006. Procesos estructuradores de las comunidades biológicas en lagunas costeras de Uruguay. En: Menafra, R., Rodriguez-Gallego, L., Scarabino, F. y Conde, D. (eds.) Bases para la conservación y el manejo de la costa uruguaya. Montevideo: Vida Silvestre. pp.611-630. ISBN: 9974-7589-2-0.

Bonilla, S. y Meerhoff, M., 2014. Informe CASAS: Calidad de agua de sistemas acuáticos superficiales. Estado actual de la calidad del agua de sistemas acuáticos superficiales en Uruguay y recomendaciones, con énfasis en la cuenca del Río Santa Lucía. Montevideo: CURE-Facultad de Ciencias, Universidad de la República. (Informe inédito). pp.22.

Bordet, F., 2009. Monitoreo emergencia de floración de cianofíceas: áreas recreativas-embalse de Salto Grande. Salto: Comisión Técnica Mixta de Salto Grande. (Informe inédito).

Britos, A., Gravier, A. y Vidal, L., 2009. Métodos de análisis de cianotoxinas en los servicios de agua potable de OSE [En línea]. En: Resúmenes del $1^{\circ}$ Encuentro Uruguayo. Cianobacterias: del conocimiento a la gestión. [Consulta: 15 de diciembre de 2014]. Montevideo: LATU; Sección Limnología, Facultad de Ciencias, Universidad de la República. Disponible en: http://limno.fcien.edu.uy/ CDCIANO2009/intro.html

Chalar, G., 2006. Dinámica de la eutrofización a diferentes escalas temporales: Embalse Salto Grande (ArgentinaUruguay). En: Tundisi, J. G., Matsumura-Tundisi, T. y C. Sidagis (eds.). Eutrophication in South America: causes, consequences and technologies for management and control. São Carlos: International Institute of Ecology. pp.87-101.

Chalar, G., De León, L., de León, R., Fabián, D. y Gorga, J., 1993. Evaluación de la eutrofización del embalse de Salto Grande. Análisis de las relaciones entre los parámetros físico-químicos y biológicos. Informe final de la primera etapa. Montevideo: Sección Limnología, Facultad de Ciencias. Convenio Comisión Técnica Mixta de Salto Grande - Universidad de la República. (Informe inédito). Chalar, G., De León, L., Brugnoli, E., Clemente, J. y Paradiso, 
M., 2002. Antecedentes y nuevos aportes al conocimiento de la estructura y dinámica del Embalse Salto Grande. En: Fernandez-Cierelli, A. y Chalar, G. (eds.). El agua en Iberoamérica: de la limnología a la gestión en Sudamérica. Buenos Aires: CYTED XVII; CETA. pp.123-142.

Chalar, G., Fabián, D., González-Piana, M. y Delbene, L., 2011a. Limnología de los embalses del Río Negro: Noviembre 2000 - Marzo 2009. Montevideo: Sección Limnología, Facultad de Ciencias, Universidad de la República. (Informe inédito).

Chalar G., Fabián D., González-Piana, M. y Delbene, L., 2011b. Caracterización limnológica de los embalses del Río Negro durante el período Setiembre 2009-Junio 2011. Montevideo: Sección Limnología, Facultad de Ciencias, Universidad de la República. (Informe inédito).

Chalar, G., Gerhard, M., González-Piana, M. y Fabián, D., 2014. Hidroquímica y eutrofización en tres embalses subtropicales en cadena. En: Marcovecchio, J. E., Botté, S. E. y Freije, R .H., Procesos geoquímicos superficiales en Sudamérica. Salamanca: Nueva Graficesa. pp.121-148. ISBN: 978-84-937437-6-5.

Chorus, I., 2012. Current approaches to cyanotoxin risk assessment, risk management and regulations in different countries. Dessau-Roßlau: Federal Environment Agency (Umweltbundesamt). ISSN: 1862-4804.

Chorus, I. y Bartram, J., 1999. Toxic cyanobacteria in water: A guide to their public health consequences, monitoring and management. Londres: E \& FN Spon. ISBN: 0419239308.

Clemente, J., Ferrari, G., Boccardi, L., Saizar, C. y Dabezies, M. J., 2009. Segundo año de estudio de las comunidades biológicas y variables abióticas en el tramo inferior del Río Uruguay. Montevideo: LATU (Informe de asesoramiento, $\mathrm{N}^{\circ}$ 1004375).

Conde, D., Fabián, D., Bonilla, S., Gorga, J. y Clemente, J., 1995. Informes III - V de los muestreos limnológicos, embalse Gabriel Terra. Montevideo: Sección Limnología, Facultad de Ciencias, Universidad de la República. (Informe inédito).

Conde, D., Gorga, J., Paradiso, M., Clemente, J., Bonilla, S. y Fabián, D., 1998. Informe XII Muestreo Limnológico Embalse Rincón del Bonete. Montevideo: Sección Limnología, Facultad de Ciencias, Universidad de la República. (Informe inédito).

Conde, D. y Sommaruga, R., 1999. A review of the state of Limnology in Uruguay. En: Gopal, J. y Wetzel, R (eds.). Limnology in developing countries 2. Nueva Delhi: International Scientific Publications/SIL. pp.1-31.

Conde, D., Arocena, R. y Rodríguez-Gallego, L., 2002. Recursos acuáticos superficiales de Uruguay: ambientes algunas problemáticas y desafíos para la gestión (I y II). En: AMBIOS, 3(10), pp. 5-9 y 4(11), pp.32-33.

Conde, D., Hein, V. y Bonilla, S., 2009. Floraciones de cianobacterias en lagunas costeras. En: Bonilla, S. (ed). Cianobacterias planctónicas del Uruguay. Manual para la identificación y medidas de gestión. Montevideo: UNESCO. (Documento técnico, 16). pp.79-80.

Cremella, B., Masdeu, M., Somma, A. y Bonilla, S., 2015. Método basado en la fluorescencia de pigmentos in vivo como nueva herramienta de monitoreo de floraciones fitoplanctónicas en Urugua. En: CARU. Libro de Resúmenes. Primeras Jornadas sobre Eutrofización y Floraciones Algales Nocivas en el Río Uruguay, Colón: CARU. [Consulta: 18 de setiembre de 2015]. Disponible en: http://www.caru.org.uy/jornadas/images/pdf/libro\%20 de-resumenes.pdf

de Figuereido, D. R., Azeiteiro, U. M., Esteves, M., Gonçalves, F. J. M. y Pereira, M. J., 2004. Microcystin-producing blooms-a serious global public health issue. En: Ecotoxicology and Environmental Safety, 59, pp.151-163.

Delbene, L., Gerhard, M., Marrero, A. y Aubriot, L., 2011. Evaluación de la calidad del agua de un lago artificial en Paso Carrasco, Canelones, CSIC- Proyecto PAIE013. Montevideo: Sección Limnología, Facultad de Ciencias, Universidad de la República. (Informe inédito).

De León, L. y Yunes, J. S., 2001. First report of a microcystincontaining bloom of the cyanobacterium Microcystis aeruginosa in the La Plata River, South America. En: Environmental Toxicology, 16(1), pp.110-112.

Deng, J. M., Qin, B. Q., Paerl, H. W., Zhang, Y. L., Ma, J. R. y Chen, Y., 2014. Earlier and warmer springs increase cyanobacterial (Microcystis spp.) blooms in subtropical Lake Taihu, China. En: Freshwater Biology, 59, pp.1076-1085.

DINAMA, 2009. Determinación de Clorofila a, by $c 1+c 2$ y Feopigmentos de Clorofila a (feofitina a) encontrados en fitoplancton de agua dulce y marina. 7004UY. Manual de procedimientos analíticos para muestras ambientales. Montevideo:DINAMA.

DINAMA-JICA, 2011. Proyecto sobre control de contaminación y calidad de agua en la cuenca del Río Santa Lucía. Informe final del proyecto. Montevideo: DINAMA, JICA.

Echenique, R. y Aguilera, A., 2009. Las floraciones de Cianobacterias en Argentina. Estado de la situación actual en distintas zonas de nuestro país. En: Giannuzzi, L. (ed.). Cianobacterias y cianotoxinas: identificación, toxicología, monitoreo y evaluación de riesgo. Corrientes: Moglia SRL. pp.53-56.

Fabre, A., Carballo, C., Hernández, E., Píriz, P., Bergamino, L., Mello, L., González, S., Pérez, G., León, J. G. y Aubriot, L., Bonilla, S. y Kruk, C., 2010. El nitrógeno y la relación zona eufótica/zona de mezcla explican la presencia de cianobacterias en pequeños lagos subtropicales, artificiales de Uruguay. En: Pan-American Journal of Aquatic Sciences, 5(1), pp.112-125.

Feola, G., Brena, B., Risso, J. y Sienra, D., 2006a. Programa de monitoreo de agua de playas de Montevideo. Informe temporada estival 2005-2006. Montevideo: Intendencia de Montevideo. (Informe técnico).

Feola, G., Brena, B., Risso, J. y Sienra, D., 2006b. Programa de monitoreo de agua de playas y de costa de Montevideo. Informe 2006. Montevideo: Intendencia de Montevideo. (Informe técnico).

Feola, G., Brena, B., Risso, J. y Sienra, D., 2007a. Programa de monitoreo de agua de playas de Montevideo. Informe temporada estival 2005-2006. Montevideo: Intendencia de Montevideo. (Informe técnico).

Feola, G., Brena, B., Risso, J. y Sienra, D., 2007b. Programa de monitoreo de agua de playas y de costa de Montevideo. Informe 2007. Montevideo: Intendencia de Montevideo. (Informe técnico).

Feola, G., Brena, B., Risso, J., Sienra, D. y Echezarreta, M., 2008a. Programa de monitoreo de agua de playas de Montevideo. Informe temporada estival 2007-2008. Montevideo: Intendencia de Montevideo. (Informe técnico).

Feola, G., Brena, B., Risso, J., Sienra, D. y Echezarreta, M., 2008 b. Programa de monitoreo de agua de playas de Montevideo. Informe temporada estival 2008-2009. Montevideo: 
Intendencia de Montevideo. (Informe técnico).

Feola, G., Brena, B., Risso, J., Sienra, D., Saona, G. y Echezarreta, M., 2010. Programa de monitoreo de agua de playas y de costa de Montevideo. Informe 2009-2010. Montevideo: Intendencia de Montevideo. (Informe técnico).

Feola, G., Brena, B., Cacho, C., Sienra, D., Saona, G., Espínola, J., D’Alessandro, B. y Espinosa, N., 2011a. Estudio de la calidad de agua, sedimento y biota del Río de la Plata Evaluación: Línea de base: Informe Anual - 2011. Montevideo: Intendencia de Montevideo. (Informe técnico).

Feola, G., Brena, B., Risso, J., Sienra, D., Echezarreta, M., Saona, G. y Rodríguez, A., 2011b. Programa de monitoreo de agua de playas y costa de Montevideo: Informe 2010-2011. Montevideo: Intendencia de Montevideo. (Informe técnico).

Feola, G., Brena, B., Risso, J., Sienra, D., Echezarreta, M., Pereira, M. y D’Alessandro, B., 2012. Programa de monitoreo de agua de playas y de costa de Montevideo. Informe 2011-2012. Montevideo: Intendencia de Montevideo. (Informe técnico).

Ferrari, G. y Vidal, L. 2006. Fitoplancton de la zona costera uruguaya: Río de la Plata y Océano Atlántico. En: Menafra, R., Rodriguez-Gallego, L., Scarabino, F. y Conde, D. (eds.). Bases para la conservación y el manejo de la costa uruguaya. Montevideo: Vida Silvestre. pp.45-56. ISBN: 9974-7589-2-0.

Ferrari, G., Pérez, M. C., Dabezies, M., Míguez, D. y Saizar, C., 2011a. Planktic Cyanobacteria in the lower Uruguay River, South America. En: Fottea, 11(1), pp.225-234.

Ferrari, G., Saizar, C., Boccardi, L., Dabezies, M. J., Clemente, J., 2011b. Informe sobre la caracterización biológica en el tramo inferior del Río Uruguay, febrero-noviembre 2011. Montevideo: LATU (Suplemento de informe de asesoramiento $\mathrm{N}^{\circ} 1263520$ ).

Ferrari, G., Saizar, C., Moreno, D., Clemente, J., Boccardi, L. y Dabezies, M. J., 2011c. Estudio de las comunidades biológicas y variables abióticas en el tramo inferior del Río Uruguay (Agosto 2009-Noviembre 2010). Montevideo: LATU (Suplemento de suplemento informe de asesoramiento $\mathrm{N}^{\circ} 1203146$ )

Giannuzzi, L., Sedan, D., Echenique, R. y Andrinolo, D., 2011. An acute case of intoxication with cyanobacteria and cyanotoxins in recreational water in Salto Grande Dam, Argentina. En: Marine Drugs, 9(11), pp.2164-2175.

González-Piana, M., Fabian, D., Delbene, L. y Chalar, G., 2011. Toxics blooms of Microcystis aeruginosa in three Rio Negro reservoirs, Uruguay. En: Harmful Algae News, 43, pp.16-17.

Gorga, J., Conde, D., Fabián, D., Bonilla, S., Clemente, J. y Paradiso, M., 1996a. Informe VI Muestreo limnológico Embalse Rincón del Bonete. Montevideo: Sección Limnología, Facultad de Ciencias, Universidad de la República. (Informe inédito).

Gorga, J., Conde, D., Bonilla, S., Fabián, D., Clemente, J. y Paradiso, M., 1996b. Informe VII Muestreo limnológico Embalse Rincón del Bonete. Montevideo: Sección Limnología, Facultad de Ciencias, Universidad de la República. (Informe inédito).

Gorga, J., Bonilla, S., Clemente, J., Conde, D., Fabián, D. y De León, R., 1996c. Informe VIII Muestreo limnológico Embalse Rincón del Bonete. Montevideo: Sección Limnología, Facultad de Ciencias, Universidad de la República. (Informe inédito).

Gorga, J., Conde, D., Bonilla, S., Fabián, D., Clemente, J. y
Paradiso, M., 1997. Informe IX Muestreo limnológico Embalse Rincón del Bonete. Montevideo: Sección Limnología, Facultad de Ciencias, Universidad de la República. (Informe inédito).

Gorga, J., Paradiso, M., Clemente, J., Bonilla, S., Fabián, D. y Conde, D., 1998. Informe XIII Muestreo limnológico Embalse Rincón del Bonete. Montevideo: Sección Limnología, Facultad de Ciencias, Universidad de la República. (Informe inédito).

Gravier, A., Vidal, L. y Britos, A., 2009. Cianobacterias como organismos interferentes en el servicio de de agua potable de Bella Unión (Uruguay) [En línea]. En: Resúmenes del $1^{\circ}$ Encuentro Uruguayo. Cianobacterias: del conocimiento a la gestión. Montevideo: LATU; Facultad de Ciencias. [Consulta: 15 de diciembre de 2014]. Disponible en: http:// limno.fcien.edu.uy/CDCIANO2009/intro.html

Hautala, H., Lamminmäki, U., Spoof, L., Nybom, S., Meriluoto, J. y Vehniäinen, M., 2013. Quantitative PCR detection and improved sample preparation of microcystin-producing Anabaena, Microcystis and Planktothrix. En: Ecotoxicology and environmental safety, 87, pp. 49-56.

International Organization for Standarization, 1992. ISO 10260: Water quality - Measurement of biochemical parameters - Spectrometric determination of the chlorophyll-a concentration. Ginebra: ISO.

Instituto Uruguayo de Normas Técnicas (Uruguay), 2008. UNIT 833: Agua potable. Requisitos. Montevideo: UNIT.

Kim, S. G., Joung, S. H., Ahn, C. Y., Ko, S. R., Boo, S. M. y Oh, H. M., 2010. Annual variation of Microcystis genotypes and their potential toxicity in water and sediment from a eutrophic reservoir. En: FEMS Microbiology Ecology, 74(1), pp.93-102.

Kruk, C., Mazzeo, N., Lacerot, G. y Reynolds, C., 2002. Classification schemes for phytoplankton: a local validation of a functional approach to the analysis of species temporal replacement. En: Journal of Plankton Research, 24, pp.901-912.

Kruk, C., Rodriguez-Gallego, L., Quintans, F., Lacerot, G., Scasso, F., Mazzeo, N., Meerhoff, M. y Paggi, J., 2006. Calidad de agua y biodiversidad de 18 pequeñas lagunas en la costa sureste de Uruguay. En: Menafra, R., Rodriguez-Gallego, L., Scarabino, F. y Conde, D. (eds.). Bases para la conservación y el manejo de la costa uruguaya. Montevideo: Vida Silvestre. pp.599-610. ISBN: 9974-7589-2-0

Kruk, C., Rodríguez-Gallego, L., Meerhoff, M., Quintans, F., Lacerot, G., Mazzeo, N., Scasso, F., Paggi, J. C., Peeters, E. T. H. M., y Marten, S., 2009. Determinants of biodiversity in subtropical shallow lakes (Atlantic coast, Uruguay). En: Freshwater Biology, 54, pp.2628-2641.

Kurmayer, R. y Gumpenberger, M., 2006. Diversity of microcystin genotypes among populations of the filamentous cyanobacteria Planktothrix rubescens and Planktothrix agardhii. En: Molecular Ecology, 15(12), pp.3849-3861.

Mazzeo, N., Crosa, D. y Sommaruga, R., 1993. Productividad y variación estacional de la biomasa de Pistia stratiotes $\mathrm{L}$. en el Reservorio del Cisne, Uruguay. En: Acta Limnológica Brasiliensia, 6, pp.186-195.

Mazzeo, N., Rodríguez-Gallego, L., Kruk, C., Meerhoff, M., Gorga, J., Lacerot, G., Quintans, F., Loureiro, M., Larrea, D. y García-Rodríguez. F., 2003. Effects of Egeria densa 
Planch. beds on a shalllow lake without piscivorous fish. En: Hydrobiologia, 506(1-3), pp.591-602.

Meerhoff, M., Clemente, J.M., Teixeira de Mello, F., Iglesias C., Pedersen, A.R. y Jeppesen, E., 2007. Can warm climate related structure of littoral predator assemblies weaken the clear water state in shallow lakes? En: Global Change Biology, 13(9), pp.1888-1897.

Moss, B., 1998. Ecology of fresh waters: man and medium, past to the future. 3. Oxford: Blackwell Science Oxford. ISBN: 0-632-03512-9.

Moss, B., Kosten, S., Meerhoff, M., Battarbee, R. W, Jeppesen, E., Mazzeo, N., Havens, K., Lacerot, G., Liu, Z., De Meester, L., Paerl H. y Scheffer, M., 2011. Allied attack: climate change and nutrient pollution. En: Inland Waters, 1(2), pp. 101-105.

Mowe, M. A. D., Mitrovic, S. M., Lim, R. P., Furey, A. y Yeo D. C. J., 2015. Tropical cyanobacterial blooms: a review of prevalence, problem taxa, toxins and influencing environmental factors. En: Journal of Limnology, 79(2), pp. 205-224.

Niedermeyer, T., 2013. Microcystin congeners described in the literature. [En línea] [Consulta: 11 de noviembre 2015]. Disponible en: http://dx.doi.org/10.6084/m9.figshare.

O'Farrell, I., Bordet, F. y Chaparro, G., 2012. Bloom forming cyanobacterial complexes co-occurring in a subtropical large reservoir: validation of dominant eco-strategies. En: Hydrobiologia, 698(1), pp.175-190.

O’Neil, J. M., Davis, T. W., Burford, M. A. y Gobler, C. J., 2012. The rise of harmful cyanobacteria blooms: The potential roles of eutrophication and climate change. En: Harmful Algae, 14, pp.313-334.

Oliver, R. y Ganf, G. G., 2000. Freshwater blooms. En: Whitton, B. A. y Potts, M. The ecology of cyanobacteria. Dordrecth: Kluwer Academic Press. pp.149-194.

Pacheco, J. P., Iglesias, C., Meerhoff, M., Fosalba, C., Goyenola, G., Teixeira-de Mello, F., García, S., Gelós, M. y GarcíaRodríguez, F., 2010. Phytoplankton community structure in five subtropical shallow lakes with different trophic status (Uruguay): a morphology-based approach. En: Hydrobiologia, 646(1), pp.187-197.

Paerl, H. W. y Otten, T. G., 2013. Harmful cyanobacterial blooms: Causes, consequences, and controls. En: Microbial Ecology, 65(4), pp.995-1010.

Pérez, M. C., Bonilla, S., De León, L., Smarda, J. y Komárek, J., 1999. A bloom of Nodularia baltica-spumigena group (Cyanobacteria) in a shallow coastal lagoon of Uruguay, South America. En: Algological Studies, 128, pp.91-101.

Piccini, C., Aubriot, L., Fabre, A., Amaral, V., González-Piana, M., Giani, A., Figueredo, C. C., Vidal, L., Kruk, C. y Bonilla, S., 2011. Genetic and eco-physiological differences of South American Cylindrospermopsis raciborskii isolates support the hypothesis of multiple ecotypes. En: Harmful Algae, 10(6), pp.644-653.

Pírez, M., Gonzalez-Sapienza, G., Sienra, D., Ferrari, G., Last, M., Last, J. y Brena, B. M., 2013. Limited analytical capacity for cyanotoxins in developing countries may hide serious environmental health problems: simple and affordable methods may be the answer. En: Journal of Environmental Management, 114, pp.63-71.

Portaria Ministério da Saúde, № 2914, de 12 de diciembre de 2011 [En línea]. [Consulta: 15 de diciembre de 2014]. Brasil. Disponible en: http://bvsms.saude.gov.br/bvs/ saudelegis/gm/2011/prt2914_12_12_2011.html

Quirós, R. y Luchini, L., 1982. Características limnológicas del embalse Salto Grande. III. Fitoplancton y su relación con parámetros ambientales. En: Revista Asociación Ciencias Naturales del Litoral, 13, pp.40-66.

Rangel, L., Silva, L.H.S., Rosa, P., Roland F. y Huszar, V.L.M., 2012. Phytoplankton biomass is mainly controlled by hydrology and phosphorus concentrations in tropical hydroelectric reservoirs. En: Hydrobiologia, 693, pp.13-28

Rigosi, A., Carey, C. C., Ibelings, B. W. y Brookes, J. D., 2014. The interaction between climate warming and eutrophication to promote cyanobacteria is dependent on trophic state and varies among taxa. En: Limnology and Oceanography, 59, pp.99-114

Rodríguez Gallego, L., 2010. Eutrofización de las lagunas costeras de Uruguay: impacto y optimización de los usos del suelo. Montevideo: Programa PEDECIBA Biología, Facultad de Ciencias, Universidad de la República. (Tesis de doctorado).

Sant'Anna, C. L., Azevedo, M. T. de P., Werner, V. R., Dogo, C. R., Rios, F. R. y de Carvalho, L. R., 2008. Review of toxic species of Cyanobacteria in Brazil. En: Algological Studies, 126(1), pp.251-265.

Scasso, F., Mazzeo, N., Gorga, J., Kruk, C., Lacerot, G., Clemente, J. y Bonilla, S., 2001. Limnological changes in a sub-tropical shallow hypertrophic lake during its restoration: two years of a whole-lake experiment. En: Aquatic Conservation: Marine and Freshwater Ecosystems, 11(1), pp.31-44.

Sienra, D y Ferrari, G., 2006. Monitoreo de cianobacterias en la costa de Montevideo (Uruguay). En: Menafra, R., Rodriguez-Gallego, L., Scarabino, F. y Conde, D. (eds.). Bases para la conservación y el manejo de la costa uruguaya. Montevideo: Vida Silvestre. pp.413-420. ISBN: 9974-7589-2-0.

Simoens, M., 2009. Microcistina - LR en el Uruguay. [En línea]. En: Resúmenes del $1^{\circ}$ Encuentro Uruguayo. Cianobacterias: del conocimiento a la gestión. Montevideo: LATU; Sección Limnología, Facultad de Ciencias, Universidad de la República. [Consulta: 15 de diciembre de 2014]. Disponible en: http://limno.fcien.edu.uy/ CDCIANO2009/intro.html/

Smith, V.H., Tilman, G.D. y Nekola, J.C., 1999. Eutrophication: impacts of excess nutrient inputs of freshwater, marine and terrestrial ecosystems. En: Environmental Pollution, 100(13), pp. 179-196.

Somma, A., 2014. El papel de la luz y la temperatura en la dinámica de cianobacterias en un lago de uso recreativo. Biológicas. Montevideo: Facultad de Ciencias, Universidad de la República. (Tesis de Licenciatura en Ciencias).

Sournia, A., 1978. Phytoplankton manual. París: UNESCO, ISBN ISSN: 93-3-101572-9. (Serie: Monographs on oceanographic methodology, Vol. 6).

Steffen, M. y Inda, H., 2010. Bases técnicas para el manejo integrado de Laguna del Sauce y cuenca asociada. Montevideo: Universidad de la República; South American Institute for Resilience and Sustainability Studies (SARAS). ISBN: 978-9974-0-0694-2.

Técnicos del LATU. Informe sobre caracterización biológica en el tramo inferior del Río Uruguay, febrero-noviembre 2012. Montevideo: LATU. (Informe de consultoría $\mathrm{N}^{\circ}$ Solicitud 1366124/MAM).

Uruguay. Decreto 253/979, de 19 de mayo de 1979. Diario Oficial, 31 de mayo de 1979, p.1473. 
Uruguay. Decreto 375/011, de 03 de noviembre de 2011. Diario Oficial, 14 de noviembre de 2011, p.1066.

van Apeldoorn, M. E., van Egmond, H. P., Speijers, G. J. A. y Bakker G. J. I., 2007. Toxins of cyanobacteria. En: Molecular Nutrition and Food Research, 51(1), pp.7-60.

Vidal, L., 2008. Estructura y biomasa del fitoplancton en lagunas costeras: Relevancia del picoplancton autótrofo. Montevideo: PEDECIBA Biología, Facultad de Ciencias, Universidad de la República. (Tesis de maestría).

Vidal, L. y Kruk, C., 2008. Cylindrospermopsis raciborskii (Cyanobacteria) extends its distribution to Latitude $34^{\circ} 53^{\prime} \mathrm{S}$ : taxonomical and ecological features in Uruguayan eutrophic lakes. En: Panamerican Journal of Aquatic Sciences, 3, pp.142-151.

Vidal, L., Britos, A. y Gravier, A., 2009. Cianobacterias planctónicas en aguas superficiales destinadas para consumo humano en Uruguay: taxonomía, distribución y toxicidad. [En línea]. En: Resúmenes del $1^{\circ}$ Encuentro Uruguayo. Cianobacterias: del conocimiento a la gestión. Montevideo: LATU; Sección Limnología, Facultad de Ciencias, Universidad de la República. [Consulta: 15 de diciembre de 2014]. Disponible en: http://limno.fcien.edu. uy/CDCIANO2009/intro.html

Vidal, L. y Britos, A., 2012. Uruguay: Occurrence, toxicity and regulation of Cyanobacteria. En: Chorus, I., (ed.). Current approaches to cyanotoxin risk assessment, risk management and regulations in different countries. Dessau-Roßlau: Federal Environment Agency (Umweltbundesamt). pp.130133. ISSN: 1862-4804.

Vidal L., Gravier A., Pérez M. C. y Britos A., 2015. Seguimiento de servicios de agua potable abastecidos por el Río Uruguay con presencia de cianobacterias potencialmente productoras de microcistinas, de acuerdo al "Protocolo de Alertas por Cianobacterias" establecido por el Área Hidrobiología del Laboratorio Central, Obras Sanitarias del Estado (OSE). [En línea] En: CARU. Libro de Resúmenes. Primeras Jornadas sobre Eutrofización y Floraciones Algales Nocivas en el Río Uruguay. Colón: CARU. [Consulta: 18 de setiembre de 2015]. Disponible en: http://www.caru.org.uy/jornadas/ images/pdf/libro\%20de-resumenes.pdflibro\%20deresumenes.pdf.

Zhou, J., Bruns, M. A. y Tiedje, J. M., 1996. DNA recovery from soils of diverse composition. En: Applied and Environmental Microbiology, 62(2), pp. 316-22.

Zurawell, R. W., Chen, H., Burke J. M. y Prepas E. E., 2005. Hepatotoxic Cyanobacteria: A review of the biological importance of Microcystins in freshwater environments. En: Journal of Toxicology and Environmental Health (B), 8, pp.1-37. 